\title{
APPLICATION OF THE PREDICTION DECONVOLUTION TECHNIQUE TO \\ SIGNAL PROCESSING IN GROUND PENETRATING RADAR SYSTEMS
}

\author{
Le Van Hung ${ }^{(1)}$, Bui Huu Phu ${ }^{(2)}$, Nguyen Thanh Duy ${ }^{(2)}$, Nguyen Thanh Nam ${ }^{(2)}$ \\ (1) University of Industry of Hochiminh City \\ (2) DCSELAB, University of Technology, VNU-HCM \\ (Manuscript Received on April $5^{\text {th }}$, 2012, Manuscript Revised November 20 ${ }^{\text {rd }}$, 2012)
}

\begin{abstract}
Ground penetrating radar $(G P R)$ systems emit electromagnetic energy into ground and receive reflection signals to process and display images of objects underground. The technology can be applied to variety of fields such as military, constructions, geophysics, ... In the paper, we will propose the prediction deconvolution technique for signal processing in GPR systems. The technique is developed based on the method of Least Square filter and Wiener filter. Our processed results have shown that by applying the proposed technique, received signals will be eliminated interference and give better images with high resolution. In addition, to get good results we see that it is necessary to predict the accuracy of pulse response of environments.
\end{abstract}

Keywords: Prediction Deconvolution Technique, Signal Processing, Ground Penetrating Radar $(G P R)$

\section{INTRODUCTION}

Ground penetrating radar (GPR) technology has been widely studied over the world. The GPR system emits electromagnetic energy into ground and receives reflection signals to process and display images of objects underground. The technology can be applied to variety of fields such as detection of buried mines, mine detection (gold, oil, underground water, ...), pipes and cable detection, evaluation of reinforced concrete, geophysical investigations, road condition survey, tunnel $\&$ wall condition, ... [1-11].

In GPR systems, transmitted signals are narrow pulses. Due to interference and characteristics of material underground, received signals are widen and delayed responses, thus reduce the resolution of GPR's image. The purpose of the deconvolutional techniques is to convert the responses into a narrow pulse in order to eliminate interference and improve the resolution $[1,2,5]$.

Signal processing techniques until now have been used techniques of image processing such as noise removal, smooth processing by two dimensional multiplication convolution, or median filter, ... [12]. However, for GPR signals, we need to not only process images but also recover transmitted narrow pulses. In the paper, we propose a method of prediction deconvolution, which can do two simultaneous 
tasks of prediction and deconvolution. The results of processing are much dependent on the prediction distance. The importance of the deconvolution technique is to process widen signals to a spike pulse. Therefore, the technique can eliminate Gaussian noise and recover signals in time domain and increase the resolution of GPR's images. The technique is based on the method of Least Square filter and Wiener filter. Our processed results have shown that by applying the proposed technique, received signals will be eliminated interference and give better images with high resolution. In addition, to get good results we see that it is needed to predict the accuracy of pulse response of environments.

The remaining of the paper is organized as follows. In the next section, the model of GPR systems is described. The proposed technique of predict convolution is presented in section 3 . In section 4, we show the process of the technique and discuss its results. Finally, we conclude the paper in section 5 .

\section{MODEL OF GPR SYSTEMS}

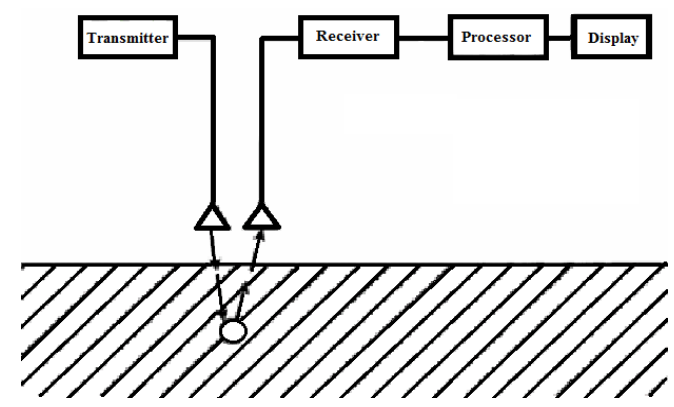

Fig. 1. Block diagram of a GPR system

GPR is a method applied electromagnetic

energy to investigate structures and

characteristics of materials underground without dig and destruction. The model of GPR systems is shown in Fig. 1. The system uses high frequency radio signals to collect information underground. Signals transmitted from antennas penetrate into ground with a velocity depended on environments. When the signals go through different layers of material with different dielectrical constants, a part of the signals is reflected. Receive antennas receive the signals and then process to view the images. Because the reflected signals are created at the border of material layers, by processing, viewing, and monitoring, we can determine the structure and shape of objects underground.

\section{THE PREDICT CONVOLUTION TECHNIQUE}

Signal processing plays an important part in GPR systems. The purpose of the signal processing techniques is to eliminate noise and interference, improve the quality of images, and locate the position of desired targets. In the paper, we propose a prediction deconvolution technique, which efficiently eliminates noise and interference, improve the quality of images. The proposed technique is developed based on a consequence of filters: Invert filter, Least Square filter, and Weiner filter.

\subsection{Invert filter}

A concept of invert filter is shown in Fig.2. If $w(t)$ is GPR wavelet signals received and $\delta(t)$ is desired output signals, then $f(t)$ must satisfy the below condition: 
$\delta(t)=w(t) * f(t)$ or $f(t)=\delta(t) * \frac{1}{w(t)}$

By conducting z-transform of (1), we have

$F(z)=\frac{1}{W(z)}=f_{0}+f_{1} z+f_{2} z^{2}+\ldots$

Where $W(z)=w_{0}+w_{1} z+w_{2} z^{2}+\ldots$

The expression shows the determination of the filter's coefficients by inverting the $\mathrm{z}$ transform of GPR wavelet. However, the filter usually gives enormous error, especially when GPR wavelet signals are different from desired signals.

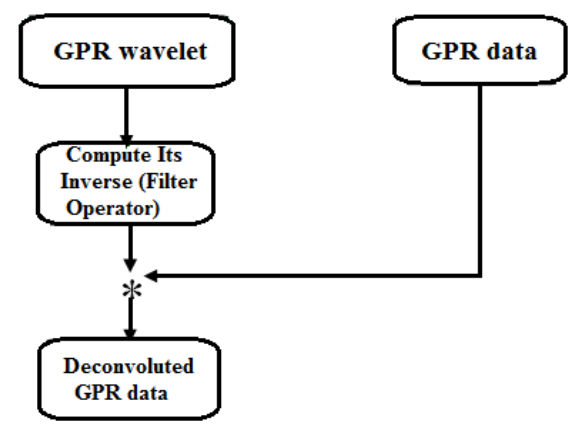

Fig. 2. Invert Filter

\subsection{Least square filter}

This is the method to find the filter's coefficients so that the difference between received signals and the desired signals is minimal. A concept of Least Square filter is shown in Fig. 3. The filter's coefficients $f_{1}$, $f_{2}, \ldots, f_{\mathrm{n}}$ are initial with arbitrary values, then convolute with GPR received signals $w(\mathrm{t})$ as:

$$
y(\mathrm{t})=w(\mathrm{t}) * f(\mathrm{t})
$$

Then, the coefficients are determined by applying the least square error algorithm for the error between signals $y(\mathrm{t})$ and desired signals $d(\mathrm{t})$ as:

$$
\underset{f_{1}, f_{2}, \ldots, f_{n}}{\arg \min \|e(t)\|^{2}=} \underset{f_{1}, f_{2}, \ldots, f_{n}}{\arg \min \|d(t)-y(t)\|^{2}}
$$

After receiving the coefficients, the filter deconvolutes again with GPR received signals to get output signals.

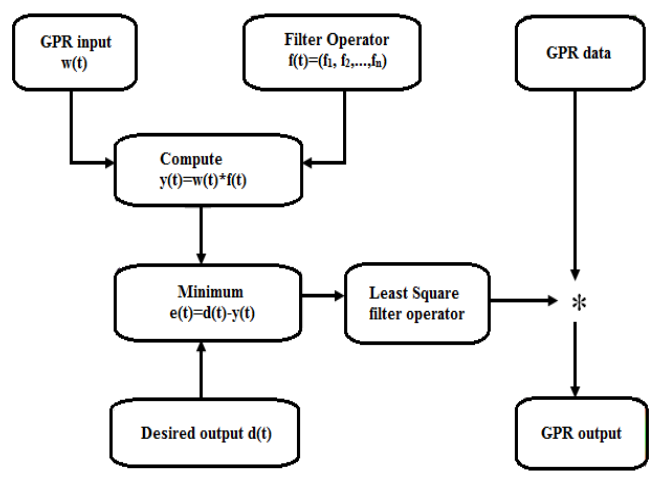

Fig. 3. Least Square Filter According to [12], the method is significantly dependent on the initial phase of desired signal $d(\mathrm{t})$. If the phase is small, then the error is small; and if the phase is large, then the error is large. In addition, the method is quite complex when the order of filter is high.

\subsection{Weiner filter}

A concept of Weiner filter is shown in Fig. 4. Assuming that received signals are $\left(x_{0}\right.$, $\left.x_{1}, \ldots, x_{\mathrm{n}-1}\right)$, desired signals are $\left(d_{0}, d_{1}, \ldots d_{\mathrm{n}-1}\right)$. The autocorrelation of received signals $\left(r_{0}, r_{1}\right.$ ,$\left.\ldots r_{\mathrm{n}-1}\right)$ is given by

$$
r_{\tau}=\sum_{t} x(t) x(t-\tau)
$$

for $n=5$ we have:

\section{Trang 54}




$$
\begin{aligned}
& r_{0}=x_{0}^{2}+x_{1}^{2}+x_{2}^{2}+x_{3}^{2}+x_{4}^{2} \\
& r_{1}=x_{0} x_{1}+x_{1} x_{2}+x_{2} x_{3}+x_{3} x_{4} \\
& r_{2}=x_{0} x_{2}+x_{1} x_{3}+x_{2} x_{4} \\
& r_{3}=x_{0} x_{3}+x_{1} x_{4} \\
& r_{4}=x_{0} x_{4} \\
& r_{5}=0
\end{aligned}
$$

The cross-correlation of received signals $\left(\mathrm{g}_{0}, g_{1}, \ldots, g_{\mathrm{n}-1}\right)$ is calculated as follows:

$$
g(\tau)=\sum_{t} x(t) d(t-\tau)
$$

The coefficients of Weiner filter $\left(\mathrm{a}_{0}\right.$, $a_{1}, \ldots, a_{n-1}$ ) can be determined by solving the below equations:

$$
\left(\begin{array}{lllll}
r_{0} & r_{1} & r_{2} & \cdots & r_{n-1} \\
r_{1} & r_{0} & r_{1} & \cdots & r_{n-2} \\
r_{2} & r_{1} & r_{0} & \cdots & r_{n-3} \\
\vdots & \vdots & \vdots & \ddots & \vdots \\
r_{n-1} & r_{n-2} & r_{n-3} & \cdots & r_{0}
\end{array}\right)\left(\begin{array}{l}
a_{0} \\
a_{1} \\
a_{2} \\
\vdots \\
a_{n-1}
\end{array}\right)=\left(\begin{array}{l}
g_{0} \\
g_{1} \\
g_{2} \\
\vdots \\
g_{n-1}
\end{array}\right)
$$

(9)

After receiving the coefficients, the filter deconvolutes again with GPR received signals to get output signals.

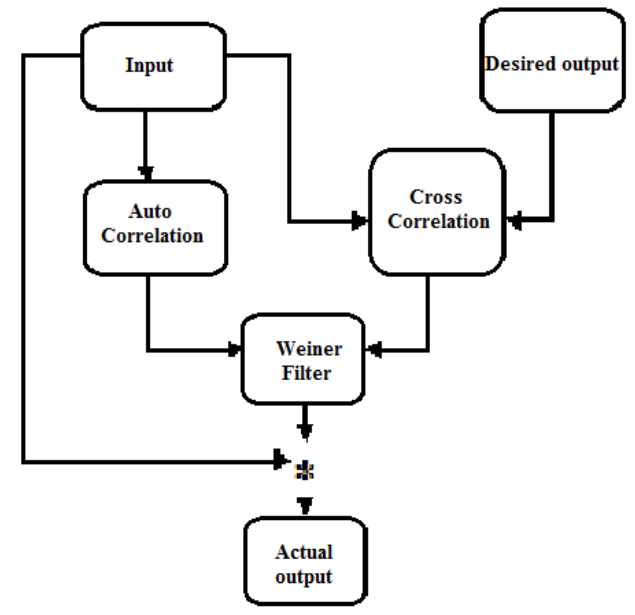

\subsection{Prediction deconvolution filter}

For the technique, the coefficients of the filter are determined so that output signals will be prediction signals considering as input signals in future. A concept of the proposed filter is shown in Fig. 5. Assuming that input signals $\quad$ are $x(t):\left(x_{0}, x_{1}, x_{2}, x_{3}, x_{4}\right)$, prediction signals are $x(t+\alpha):\left(x_{2}, x_{3}, x_{4}\right)$ with $\alpha=2$ The coefficients of the filter are determined by solving the linear equations below:

$$
r(\alpha+\tau)=\sum_{t} x(t) x(t+\alpha-\tau)
$$

Or

$$
\left(\begin{array}{lllll}
r_{0} & r_{1} & r_{2} & \cdots & r_{n-1} \\
r_{1} & r_{0} & r_{1} & \cdots & r_{n-2} \\
r_{2} & r_{1} & r_{0} & \cdots & r_{n-3} \\
\vdots & \vdots & \vdots & \ddots & \vdots \\
r_{n-1} & r_{n-2} & r_{n-3} & \cdots & r_{0}
\end{array}\right)\left(\begin{array}{l}
a_{0} \\
a_{1} \\
a_{2} \\
\vdots \\
a_{n-1}
\end{array}\right)=\left(\begin{array}{l}
r_{\alpha} \\
r_{\alpha+1} \\
r_{\alpha+2} \\
\vdots \\
r_{\alpha+n-1}
\end{array}\right)
$$

Now, consider special case $\alpha=1, n=5$ we have

$$
\left(\begin{array}{lllll}
r_{0} & r_{1} & r_{2} & r_{3} & r_{4} \\
r_{1} & r_{0} & r_{1} & r_{2} & r_{3} \\
r_{2} & r_{1} & r_{0} & r_{1} & r_{2} \\
r_{3} & r_{2} & r_{1} & r_{0} & r_{1} \\
r_{4} & r_{3} & r_{2} & r_{1} & r_{0}
\end{array}\right)\left(\begin{array}{l}
a_{0} \\
a_{1} \\
a_{2} \\
a_{3} \\
a_{4}
\end{array}\right)=\left(\begin{array}{l}
r_{1} \\
r_{2} \\
r_{3} \\
r_{4} \\
r_{5}
\end{array}\right)
$$

By augmenting the right side to the left side we obtain

Fig. 4. Wiener Filter application for GPR data 


$$
\left(\begin{array}{llllll}
-r_{1} & r_{0} & r_{1} & r_{2} & r_{3} & r_{4} \\
-r_{2} & r_{1} & r_{0} & r_{1} & r_{2} & r_{3} \\
-r_{3} & r_{2} & r_{1} & r_{0} & r_{1} & r_{2} \\
-r_{4} & r_{3} & r_{2} & r_{1} & r_{0} & r_{1} \\
-r_{5} & r_{4} & r_{3} & r_{2} & r_{1} & r_{0}
\end{array}\right)\left(\begin{array}{l}
1 \\
a_{0} \\
a_{1} \\
a_{2} \\
a_{3} \\
a_{4}
\end{array}\right)=\left(\begin{array}{l}
0 \\
0 \\
0 \\
0 \\
0
\end{array}\right)
$$

(11-b)

After changing and rearranging the equations, we have new equations as follows:

$$
\left(\begin{array}{llllll}
r_{0} & r_{1} & r_{2} & r_{3} & r_{4} & r_{5} \\
r_{1} & r_{0} & r_{1} & r_{2} & r_{3} & r_{4} \\
r_{2} & r_{1} & r_{0} & r_{1} & r_{2} & r_{3} \\
r_{3} & r_{2} & r_{1} & r_{0} & r_{1} & r_{2} \\
r_{4} & r_{3} & r_{2} & r_{1} & r_{0} & r_{1} \\
r_{5} & r_{4} & r_{3} & r_{2} & r_{1} & r_{0}
\end{array}\right)\left(\begin{array}{l}
b_{0} \\
b_{1} \\
b_{2} \\
b_{3} \\
b_{4} \\
b_{5}
\end{array}\right)=\left(\begin{array}{l}
L \\
0 \\
0 \\
0 \\
0 \\
0
\end{array}\right)
$$

where $\quad b_{0}=1, b_{i}=-a_{i} \quad i=1,2,3,4,5$, $\mathrm{L}=\mathrm{r}_{0}-\mathrm{r}_{1} \mathrm{a}_{0}-\mathrm{r}_{2} \mathrm{a}_{1}-\mathrm{r}_{3} \mathrm{a}_{2}-\mathrm{r}_{4} \mathrm{a}_{3}-\mathrm{r}_{5} \mathrm{a}_{4}$

From equations (12), we see that prediction deconvolution filter is based on signals in current time and received signals in future time. When determining the coefficients of Weiner filter, we can also know the coefficients of prediction deconvolution filter.

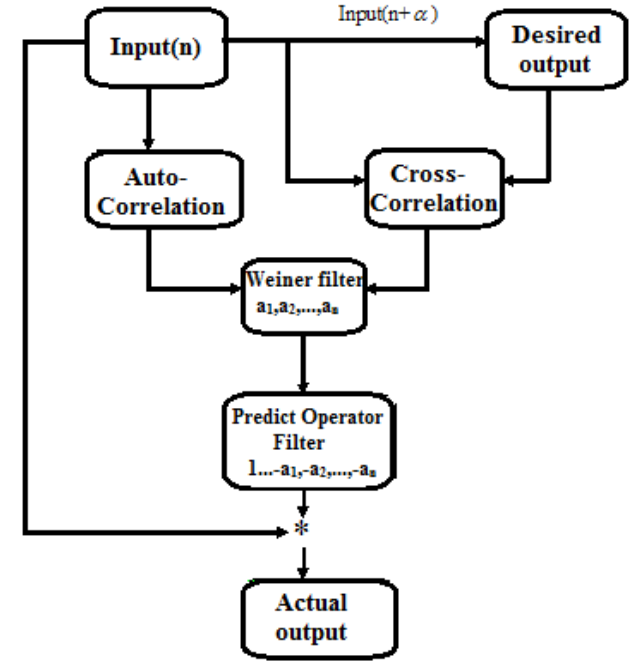

Fig. 5. Prediction deconvolution filter

\section{SIMULATION RESULTS}

In the section, we apply the prediction deconvolution filter to a real GPR data obtained by Malags systems [13]. The technique is carried out by using Matlab software. The results are compared with original data to evaluate the proposed filter. The structure of GPR data includes 510x2147 data matrices, where 510 is data obtained in time domain, and 2147 is the numbers of traces obtained in different positions.

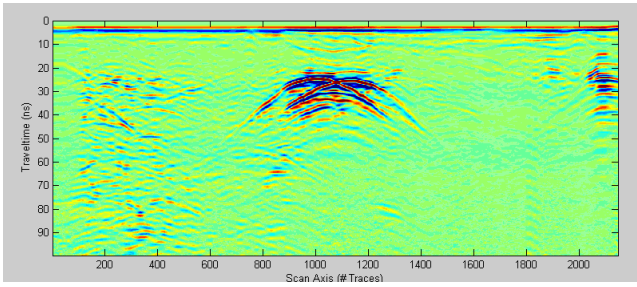

Fig. 6. Original data without processing 


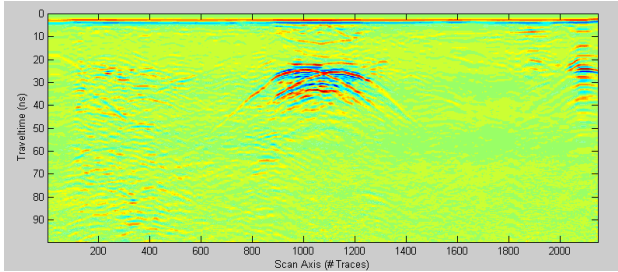

Fig. 7. Apply the prediction deconvolution filter to data with length of filter $\mathrm{L}=3 \mathrm{~ns}$, prediction range $\alpha=2$ ns, and whitening ratio $\mathrm{W}=1 \%$

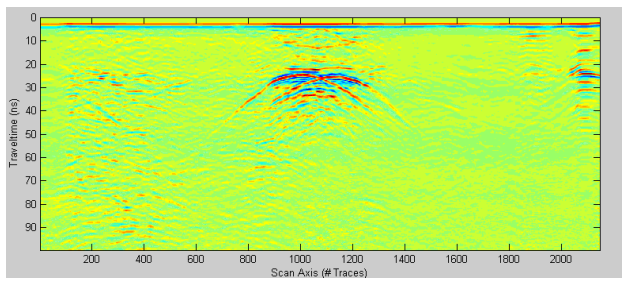

Fig. 8. Apply the prediction deconvolution filter to data with length of filter $\mathrm{L}=15 \mathrm{~ns}$, prediction range $\alpha=2 \mathrm{~ns}$, and whitening ratio $\mathrm{W}=1 \%$

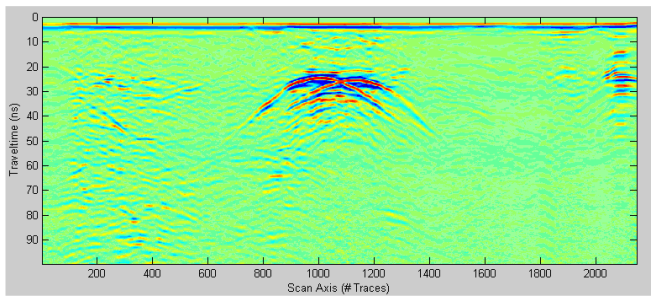

Fig. 9. Apply the prediction deconvolution filter to data with length of filter $\mathrm{L}=10 \mathrm{~ns}$, prediction range $\alpha=5 \mathrm{~ns}$, and whitening ratio $\mathrm{W}=1 \%$

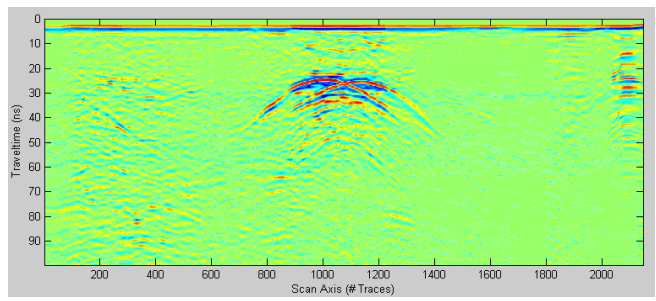

Fig. 10. Apply the prediction deconvolution filter to data with length of filter $\mathrm{L}=20 \mathrm{~ns}$, prediction range $\alpha=5 \mathrm{~ns}$, and whitening ratio $\mathrm{W}=1 \%$

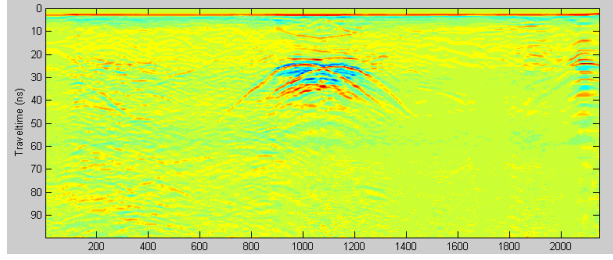

Fig. 11. Apply the prediction deconvolution filter to data with length of filter $\mathrm{L}=5 \mathrm{~ns}$, prediction range $\alpha=5 \mathrm{~ns}$, and whitening ratio $\mathrm{W}=2 \%$

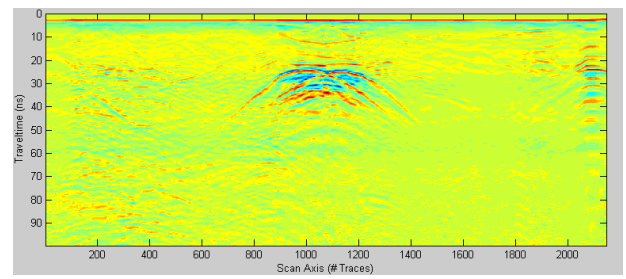

Fig. 12. Apply the prediction deconvolution filter to data with length of filter $\mathrm{L}=5 \mathrm{~ns}$, prediction range $\alpha=1 \mathrm{~ns}$, and whitening ratio $\mathrm{W}=5 \%$

From the results shown in Figs. 6 - 12, we can see that applying the prediction deconvolution filter, interference is much eliminated and the quality of image is much improved. In addition, the filter is much dependent on channel responses. If channel responses are fast, prediction range should be chosen short, otherwise if channel responses is slow, then prediction range should be chosen longer. Moreover, it is seen that the deconvolution for GPR data is mainly dependent on prediction range. Other parameters are only conditions for us to predict without affecting to processing results. The prediction filter is a technique to determine channel responses if we can obtain the optimal processing results for arbitrary prediction range. 


\section{CONCLUSIONS}

In the paper, we focus on our proposed prediction deconvolution filter. The filter is developed based on some filters such as invert filter, Least Square filter, and Weiner filter. Based on the processed results, we can see that by applying the prediction deconvolution filter, interference is much eliminated and the quality of image is much improved.

\title{
ÚNG DỤNG KỸ THUẬT GIẢI CHẬP DỤ๋ ĐOÁN CHO XỬ LÝ TÍN HIỆU TRONG HỆ THỐNG RADAR XUYÊN ĐÂT
}

\author{
Lê Văn Hùng ${ }^{(1)}$, Bùi Hũu Phứ(2) Nguyễn Thành Duy $^{(2)}$, Nguyễn Thành Nam ${ }^{(2)}$ \\ (1) Đại Học Công Nghiệp Tp. Hồ Chí Minh
}

(2) Phòng thí nghiệm Trọng điểm Quốc gia Điểu khiển số và Kỹ thuật hệ thống, Trường ĐHBK

TÓM TĂT: Hệ thống radar xuyên đất truyền năng luợng song điện tù trương vào trong lòng đất và thu tín hiệu phản xạ trở về để xủ lý và hiển thị hình ảnh của nhũng vật thể duới lòng đất. Công nghệ này có thể được áp dụng trong nhiều lĩnh vục khác nhau nhu trong quốc phòng, xây dụng và địa chất ... Trong bài báo này, chúng tôi xin đề xuất một kỹ thuật giải chập dụ đoán cho xử lý tín hiệu trong hệ thống radar xuyên đất. Kỹ thuật này được phát triển dựa trên phuơng pháp lọc bình phuơng cực tiểu và lọc Wiener. Các kết quả xử lý đã chỉ ra rằng, với việc áp dụng kỹ thuật giải chập dụ đoán, tín hiệu thu được đã loại bỏ được can nhiễu và cho bưc ảnh tốt hơn với độ phân giải cao. Hơn nũa để đạt được kết quả tốt hơn chúng tôi thấy rằng kỹ thuật này cần dụ đoán đúng chính xác đáp ứng xung của môi truờng truyền.

Tù Khóa: kỹ thuật giải chập dự đoán, xủ lý tín hiệu, radar xuyên đất.

\section{REFERENCES}

[1]. Harry M.J, Ground Penetrating Radar Theory and Applications (2009).

[2]. David J. D, Ground Penetrating Radar (2004).

[3]. Jeffrey J. D, Ground Penetrating Radar Fundamentals (2000).
[4]. Webb D. J, Todd L., Ground Penetrating Radar, Steve Cardimona

[5]. Bassem R. M, Radar Systems Analysis and Design Using MATLAB (2000).

[6]. Dicter G., Metal detector handbook for humanitarian demining (2003).

\section{Trang 58}


[7]. Lieutenant C. K. K, Detector and personal protective equipment catalogue (2009).

[8]. Jacqueline M., Alternatives for tank mine detection, RAND (2003).

[9]. Annan A. P, GPR-History, Trends, and Future Developments, Subsurface Sensing Technologies and Applications, 3, 4 ( 2002).

[10]. Xiaoyin X., Eric L. M., Adaptive Difference of Gaussians to Improve Subsurface Object Detection Using GPR
Imagery, Proc. International Conference of Image Processing, 2, 457- 460 (2002).

[11]. Faezeh S.A.G., Abrishamian M.S., $A$ novel method for FDTD numerical GPR imaging of arbitrary shapes based on Fourier transform, NDT\&E International, 40, 2, 140-146 (2007).

[12]. Ozdogan Y., Seismic Data Processing, Society of Exploration Geophysicists (2000).

[13]. www.malags.com 